\title{
Estimation Method for Ice load of Managed Ice in an Oblique Condition
}

\author{
Hyunsoo Kim ${ }^{*}$ and Jae-bin Lee ${ }^{* *}$ \\ "Department of Ship and Ocean System, Inha Technical College, Incheon, Korea \\ "Department of Naval Architecture and Ocean Engineering, Inha University, Incheon, Korea

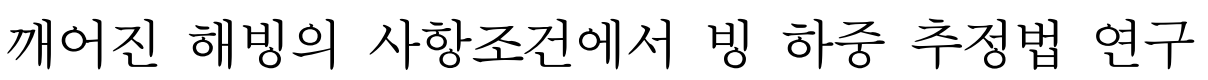 \\ 김현수 ${ }^{*}$ 이재빈( \\ "인하공업전문대학 조선해양과 \\ "인하대학교 조선해양공학과
}

KEY WORDS: Ice load 빙 하중, Oblique condition 사항조건, Ice breaker 쇄빙선, Pack ice 빙편, Arctic ocean 북극해

\begin{abstract}
Recently, as sea ice in the Arctic has been decreasing due to global warming, it has become easier to develop oil and gas resources buried in the Arctic region. As a result, Russia, the United States, and other Arctic coastal states are increasingly interested in the development of oil and gas resources, and the demand for offshore structures to support Arctic sea resources development is expected to significantly increase. Since offshore structures operating in Arctic regions need to secure safety against various drifting ice conditions, the concept of an ice-strengthened design is introduced here, with a priority on calculation of ice load. Although research on the estimation of ice load has been carried out all over the world, most ice-load studies have been limited to estimating the ice load of the icebreaker in a non-oblique state. Meanwhile, in the case of Arctic offshore structures, although it is also necessary to estimate the ice load according to oblique angles, the overall research on this topic is insufficient. In this paper, we suggest algorithms for calculating the ice load of managed ice (pack ice, 100\% concentration) in an oblique state, and discuss validity. The effect of oblique angle according to estimated ice load with various oblique angles was also analyzed, along with the impact of ship speed and ice thickness on ice load.
\end{abstract}

\section{1. 서 론}

지구 온난화로 북극의 해빙이 가속화되면서 전 세계적으로 북극지역 자원 개발 가능성에 대한 관심이 증가하고 있다. 기온 상승에 따른 북극 해빙 면적의 감소 속도는 이론적인 기후 모 델을 이용한 추정치보다 빠르게 나타나고 있어 북극지역 자원 개발 사업화 가능시점도 2020 년 전후로 예상되고 있다. 실제로 러시아에서 출발한 쇄빙수송선이 단독으로 북극해를 통과하여 기존 항로에 비해 $30 \%$ 단축된 시간에 충남 보령에 도착한 사례 가 있다. 또한 미국 지질조사국(USGS, United States Geological Survey)의 북극 자원 탐사보고서에 따르면 지금까지 발견되지 않은 석유와 가스의 약 $22 \%$ 가 북극에 매장되어 있는 것으로 밝 혀지면서, 북극해 연안국들(러시아, 미국, 캐나다 등)은 북극지 역 자원개발을 위한 극지용 해양구조물의 수요가 크게 증대될 것으로 예상하고 있다.
북극 해양구조물은 빙해에 노출되어 있으므로 빙에 의한 외 부 충격으로부터 해양구조물의 안전성을 확보하기 위해 해양구 조물에 작용하는 빙 하중 산출이 우선적으로 고려되어야 한다. 빙 하중 산정에 관한 연구는 세계 각국에서 진행되어 왔지만, 기존까지 이루 $100 \%$ concentration어진 대부분의 연구는 쇄빙선 박이 빙 해역을 통과할 때의 추진력을 계산하기 위한 빙 하중 추정과 쇄빙선박의 쇄빙성능 관점에 대해서 진행되어 왔다. 최 근까지 모형시험을 통해 쇄빙선박에 대한 빙 하중을 추정하기 위한 연구가 발표되고 있으며(Jian and Li, 2015; Jeong et al., 2017), 한편 사항각도에 따른 빙 하중을 추정하기 위해서 평탄 빙에 대해서 모형시험을 통해 빙 하중을 분석한 연구가 진행되 어 왔다(Li et al., 2013). 그러나 실제로 극지 해양구조물의 경우 다양한 방향에서 접근하는 유빙과의 충돌이 발생하기 때문에 유빙의 충돌로 인한 피해를 최소화하기 위한 연구가 필요하다. 즉, 유빙 조건에 대한 다양한 사항각도에 따른 해양구조물의 빙

Received 5 January 2018, revised 16 June 2018, accepted 22 June 2018

Corresponding author Jae-bin Lee: +82-032-860-7346, beeny06@gmail.com ORCID: https://orcid.org/0000-0002-7224-0770 It is noted that this paper is revised edition based on proceedings of KSOE 2017 in Geojedo.

(c) 2018, The Korean Society of Ocean Engineers

This is an open access article distributed under the terms of the creative commons attribution non-commercial license (http://creativecommons.org/licenses/by-nc/3.0) which permits unrestricted non-commercial use, distribution, and reproduction in any medium, provided the original work is properly cited. 
하중 산정이 요구되지만, 현재까지 이에 대한 연구는 미비한 실 정이다.

본 논문에서는 극지 해양 분야의 빙 하중 예측 기술을 정립하 기 위해서 빙 하중 추정에 관한 이론을 설명하고, 기 발표된 경 험식을 기반으로 다양한 빙 입사 조건에 대한 수정된 빙 하중 계산식을 제시하고 타당성을 검토하였다. 또한, 유빙 조건 중에 서 빙편(Pack ice, $100 \%$ concentration)에 대해 다양한 사항각도 에 따른 극지용 FPU(Floating production unit) 선형의 빙 하중을 산정하여 사항각도가 빙 하중에 미치는 영향을 분석하였다. 마 지막으로 선속 및 빙 두께에 따른 빙 하중을 계산하여, 임의의 사항각도에서 선속 및 두께가 빙 하중에 미치는 영향을 확인하 였다.

\section{2. 빙편(Pack ice, $100 \%$ concentration)에 대한 사항조건에서 빙 하중 추정법}

빙편 중에서 집적도 $100 \%$ 를 Pre-sawn이라 하며, 이에 대한 빙 하중을 계산하기 위해서 기 개발된 평탄빙에 대한 빙 하중 추정 알고리즘(Kim et al., 2013; Kim et al., 2014)을 기반의 빙 하중 추정 알고리즘을 개발하였다. 비사항조건에서 빙편에 대한 빙 하중 추 정 알고리즘은 모형시험을 통해 비교 검증(Kim et al., 2017)된 것으 로 사항조건에 적합하도록 수정 및 변형하였다. Fig. 1은 비사항조 건에서 Araon 쇄빙선에 대한 Pre-sawn, 즉 Pack ice 직접도 $100 \%$ 에 대한 빙 하중 모형시험을 수중에서 촬영한 사진이다.

기 개발된 평탄빙(Level ice)에 대한 비사항조건에서의 발생하 는 전체 빙 하중 추정 알고리즘 구성방정식은 Spencer(Spencer, 1992) 추정 이론을 기반으로 하였으며, 평탄 빙에 대한 비사항 조건의 빙 하중 모형실험과 비교 검증을 통해 각각의 다른 경 험식을 적용하여 빙 하중의 정확도를 향상하였다. 평탄빙에 대 한 전체 빙 하중은 다음 식 (1)과 같이 4개의 독립적인 빙 하중 성분들의 선형합으로 산출된다.

$$
R_{T}=R_{O W}+R_{B U}+R_{C L}+R_{B R}
$$

여기서 $R_{B U}$ 는 선체 밑으로 흘러들어간 얼음의 부력에 의해 발 생하는 부력 하중으로 Enkvist(Enkvist, 1972)의 추정법을 적용하

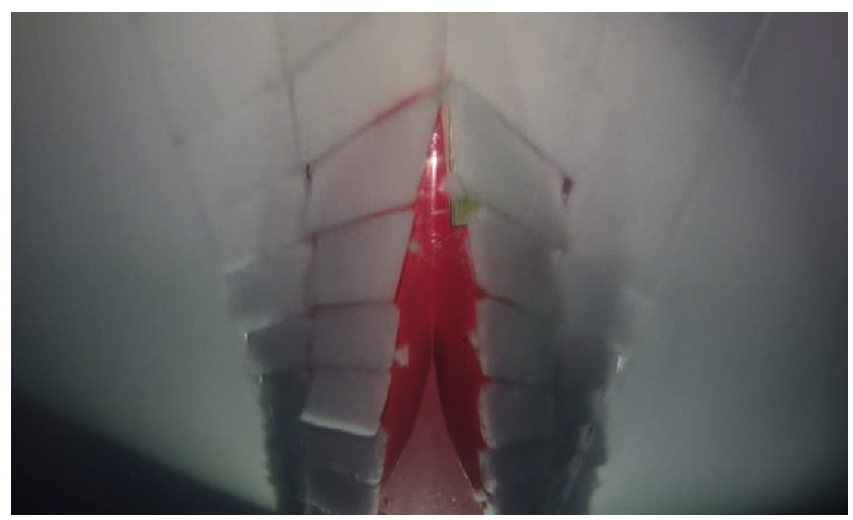

Fig. 1 An underWater view of a photograph of the pre-sawn ice (Kim et al., 2017)
였으며, $R_{C L}$ 은 선체의 진행방향에 존재하는 얼음 조각들을 밀 어내며 발생하는 빙 제거 하중으로 Ionov(Poznyak and Ionov, 1981)의 추정법을 적용하였다. 그리고 쇄빙 하중인 $R_{B R}$ 은 평평 한 얼음판을 부술 때 발생하는 것으로 Shimanskii(Shimanskii, $1938)$ 의 경험식을 이용하였다. 한편, 유체 하중 $\left(R_{O W}\right)$ 은 선체와 유체 사이의 점성에 의해 발생하는 하중으로 전제 빙 하중에서 매우 작은 비중을 차지하고 있기 때문에 기 개발된 빙 하중 알 고리즘에서는 고려하지 않았으며, 나머지 3가지 빙 하중 요소 $\left(R_{B U}, R_{B R}\right.$, 그리고 $\left.R_{O W}\right)$ 의 합으로 평탄빙에서의 빙 하중 추정 식을 구성하였다.

식 (1)에서 전체 빙 하중은 각각의 빙 하중 요소들의 선형합 으로 계산되기 때문에, 각각의 빙 하중 요소들은 서로 독립적이 다. 그러므로 쇄빙 하중인 $R_{B R}$ 을 전체 빙 하중 구성방정식에서 제외함으로써 Pre-sawn의 사항조건에서 전체 빙 하중을 계산할 수 있으며, 언급한 유체 하중을 제외하여 최종적으로 다음 식 (2)와 같이 정의된다.

$$
R_{T}=R_{C L}+R_{B R}
$$

Pre-sawn의 전체 빙 하중을 계산하기 위해 빙 제거 하중은 Ionov의 추정법을 이용하여 계산하였으며, 아래의 식 (3)과 같이 정의된다.

$$
R_{C L}=2 \rho_{i} g h B \cdot \operatorname{Fr}_{B}\left[K_{3}^{\prime} \int_{0}^{L / 2} \frac{\left[y^{\prime}(x)\right]^{2}}{\cos \alpha} d x+K_{3}^{\prime \prime} f_{g} \int_{0}^{L / 2} \frac{y^{\prime}(x)}{\cos \alpha} d x\right] \text { (3) }
$$

여기서 $y$ 는 선폭을 나타내는 길이 함수, $\rho_{i}$ 는 얼음의 밀도, $h$ 는 빙 두께, $f_{g}$ 는 마찰계수, 그리고 $g$ 는 중력가속도이고 $K_{3}^{\prime}$ 와 $K_{3}^{\prime \prime}$ 는 실험적 경험으로 결정되는 계수로 각각 1.0 와 0.5 이다. $F_{B}$ 는 선체 의 폭 $B$ 와 중력가속도 $g$ 에 대한 프루드수(Froude number)로 식 (4)에 나타내었으며, 빙 제거 하중의 경우에만 계산되는 파라미터 $V_{S}$ 는 선속으로 빙 제거 하중에 비례한다.

$$
F r_{B}=\sqrt{\frac{V_{S}}{g B}}
$$

Fig. 2에 빙 하중을 계산하기 위한 선체 흘수(Draft)에 해당하는 Water line과 Section line을 도식화하였으며, Water line과 Section line 위의 임의의 빙 하중 계산점에 대해서 기준축과의 각도 $\alpha$ 와 $\beta$ 를 나타내었다. 식 (3)으로 정의된 빙 제거 하중 추정식의 파라 미터인 $\alpha$ 는 Fig. 2 에 나타낸 바와 같이 정의되며 Water line의 선 수형상을 결정하는 주요 파라미터이다.

본 논문에서 제시하고자하는 사항조건을 고려하면 빙 제거 하중은 Fig. 3 과 같이 나타낼 수 있다. 여기서 Water line의 임의 의 빙 하중 계산점에 대해서 기준축과의 각도 $\alpha$ 는 사항각도 $\theta$ 만큼 회전하여 새로운 $\alpha^{\prime}$ 으로 정의된다. Fig. 3 에 나타낸 바와 같이, 기존의 비사항조건에서는 $B / 2$ 는 Water line에서 추진축과 의 최대거리로 정의되지만, 사항조건에서는 추진축에서 선수를 중심으로 사항각도 $\theta$ 만큼 회전하여 추진축과의 최대거리는 $W_{\max } / 2$ 로 가정할 수 있다. 사항각도 $\theta$ 만큼 회전 시 기준축 $x$ 축 

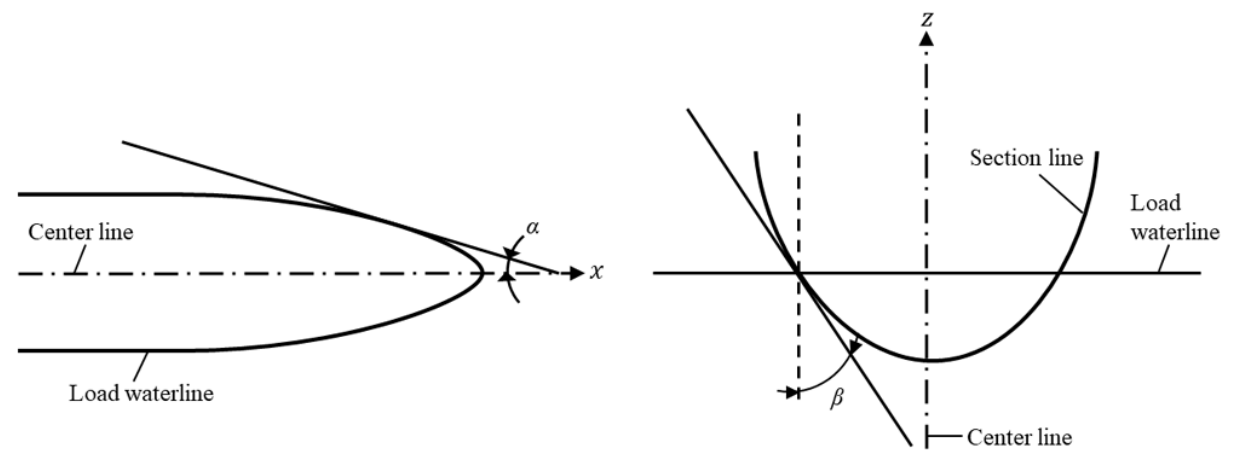

Fig. 2 The definition of the parameter for ice load

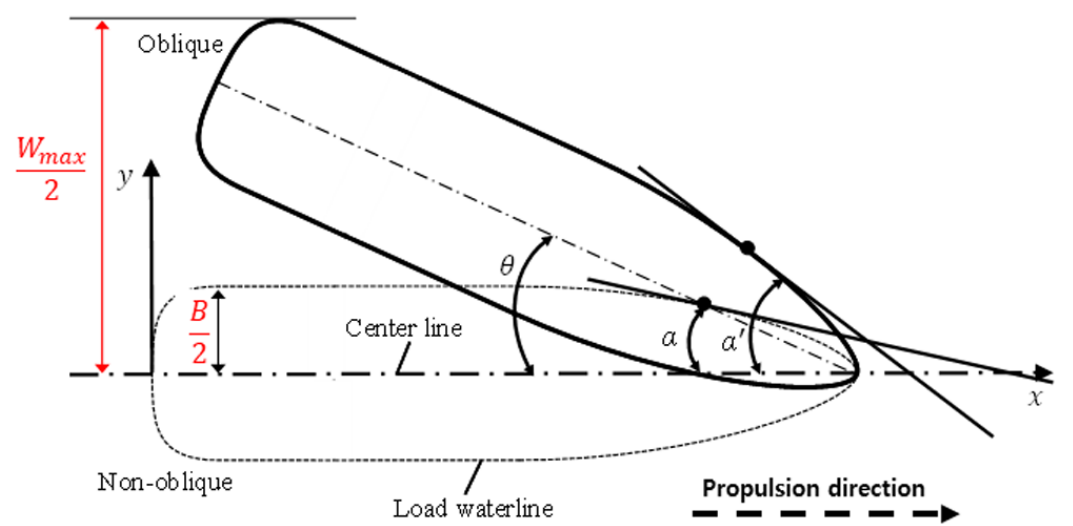

Fig. 3 Schematic of $\alpha^{\prime}$ and $W_{\max }$ in oblique condition

과의 각도 $\alpha$ 와 배의 폭 $B$ 의 변화를 도식적으로 나타내었으며, 기준축 $x$ 는 배의 추진방향 또는 얼음의 진행방향이다. 기존 비 사항조건에서의 빙 제거 하중 추정식인 식 (3)-(4)는 사항조건에 서의 수정된 빙 제거 하중 추정식, 식 (5)로 정의하였다.

$$
\begin{aligned}
& R_{C L}=2 \rho_{i} g h W_{\max } F r_{W_{\max }}\left[K_{3}^{\prime} \int_{0}^{L / 2} \frac{\left[y^{\prime}(x)\right]^{2}}{\cos \alpha} d x+K_{3}^{\prime \prime} f_{g} \int_{0}^{L / 2} \frac{y^{\prime}(x)}{\cos \alpha} d x\right] \\
& F r_{W_{\max }}=\sqrt{\frac{V_{S}}{g \cdot W_{\max }}} \\
& W_{\max }=L \sin \theta+0.5 B \cos \theta
\end{aligned}
$$

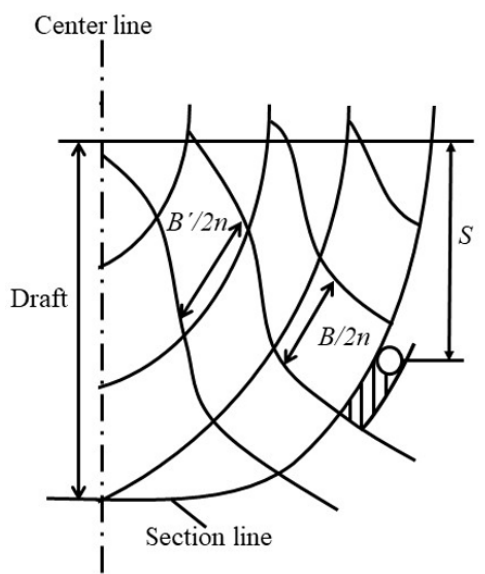

Fig. 4 Schematic of Section line for buoyancy ice load
부력 하중의 경우에는 Enkvist의 추정법을 적용하여 아래의 식 (6)과 같이 정의되며, Fig. 2에서 언급한바와 같이 Section line 위의 임의의 빙 하중 계산점에서 기준축(흘수 방향)과의 각 도 $\beta$ 를 빙편 기준으로 Fig. 4에 구체적으로 나타내었다. $R_{s p}$ 는 빙편의 위치에너지에 의한 하중성분이며, $R_{s f}$ 는 선체와 얼음사 이의 마찰에 의한 하중으로 두 가지 성분의 합으로 정의된다.

$$
\begin{aligned}
& R_{B U}=R_{s p}+R_{s f} \\
& R_{s p}=\frac{\sum_{0}^{L / 2} L_{i} \sum_{0}^{B} \rho_{\Delta} g h \bar{s} b_{i}}{L / 2}, R_{s f}=\sum_{0}^{L / 2} L_{i} \sum_{0}^{B} f_{g} \rho_{\triangle} g h b_{i} \sin \beta
\end{aligned}
$$

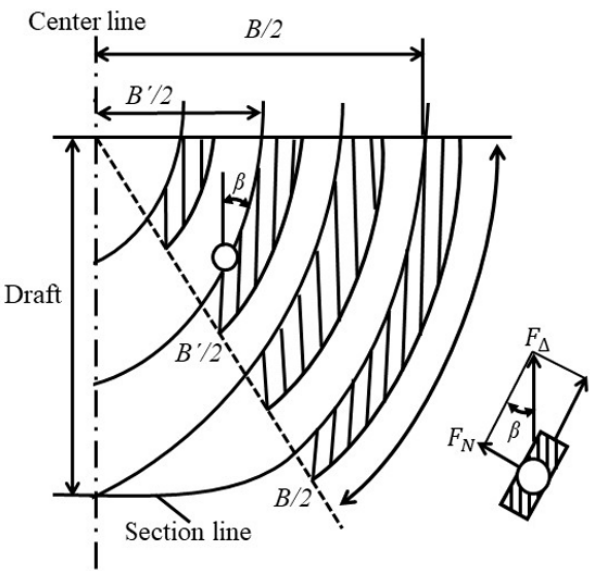




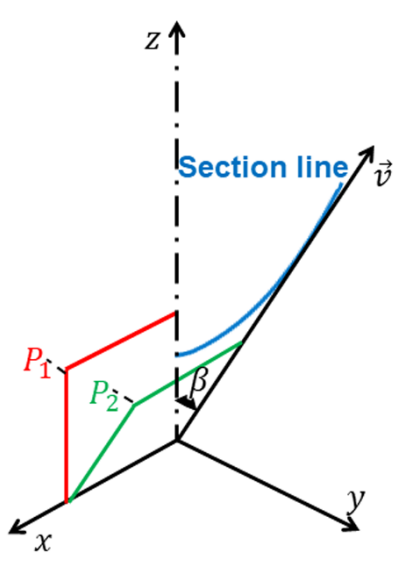

(a) Non-oblique condition

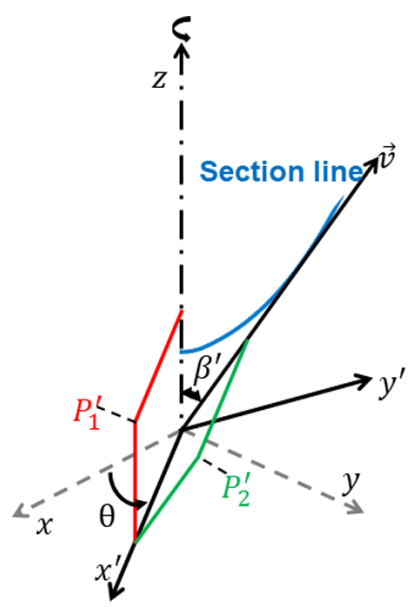

(b) Oblique condition

Fig. 5 Schematic of $\beta^{\prime}$ in oblique condition for buoyancy ice load

여기서 $\rho_{\Delta}$ 는 물과 얼음의 밀도차이를 나타내며, $L_{i}$ 는 각 Section line 사이의 길이, $b_{i}$ 는 각 Section line의 둘레 길이이고, $\bar{s}$ 는 얼음조 각이 물에 잠긴 평균 깊이를 나타낸다. $h$ 는 빙 두께, $g$ 는 중력가속 도, $B$ 는 선체의 폭, 그리고 $f_{g}$ 는 마찰계수를 나타낸다.

사항조건 적용 시에는 선박의 Section line이 기준축(흘수 방 향)에 대해서 사항각도 $\theta$ 만큼 회전하며, 회전으로 변환된 Section line의 기하하적 정보들이 부력 하중 추정 경험식 식 (6) 에 적용된다. 이 때, 기준축(흘수 방향)에 대하여 좌우 비대칭 현상이 발생한다. Fig. 5는 사항각도 적용 전후에 대한 $\beta$ 가 다 르게 추출되는 것을 도식적으로 나타내었다. Fig. 5(a)는 비사항 조건일 때 $P_{1}$ 평면과 $P_{2}$ 평면 사이의 각을 구하여 $\beta$ 를 도출할 수 있으며, Fig. 5(b)는 사항각도 $\theta$ 만큼 회전하였을 경우 회전변 환된 $P_{1}^{\prime}$ 평면과 $P_{2}^{\prime}$ 평면사이의 각을 구하여 사항된 $\beta^{\prime}$ 을 도출할 수 있다.

\section{3. 사항조건의 빙 하중 추정 프로시저}

앞장에서 언급한 경험식을 기반으로 사항조건에 적용 가능한 알고리즘을 정립하였고, 기 개발된 프로그램을 활용하여 사항 조건의 빙 제거 하중과 부력 하중을 계산하여 Pre-sawn의 전체 빙 하중을 추정하였다. 기 개발된 프로그램은 비사항조건의 빙 하중 추정 모듈을 기반으로 모형실험과 비교검증을 통해 평균 약 $10 \%$ 의 정확도를 보였다(Kim et al., 2014). 본 논문에서는 비 사항조건의 빙 하중 추정 모듈을 사항각도에 따른 선형데이터 가 출력 가능하도록 수정하여 사항조건의 빙 하중 추정 모듈을 개발하였으며, 사항조건의 빙 하중 추정 순서는 Fig. 6에 나타내 었다. 우선 빙 하중 추정 대상을 실스케일로 $3 \mathrm{D}$ 모델링하여 선 형정보 추출 모듈을 통해 Section line과 Water line의 정보를 추 출한다. Section line은 추진방향 또는 얼음의 진행방향에 대해 수직하게 교차하는 선형의 단면 라인으로, 이 라인에서 추출되 는 데이터는 부력 하중 추정식에 적용된다. Water line은 선형의 흘수에 해당하는 라인으로, 이 라인에서 추출되는 데이터는 수 정된 빙 제거 하중 추정식에 적용된다. 사항조건에서의 빙 하중 추정 알고리즘은 비사항조건에서의 빙 하중 추정 알고리즘과

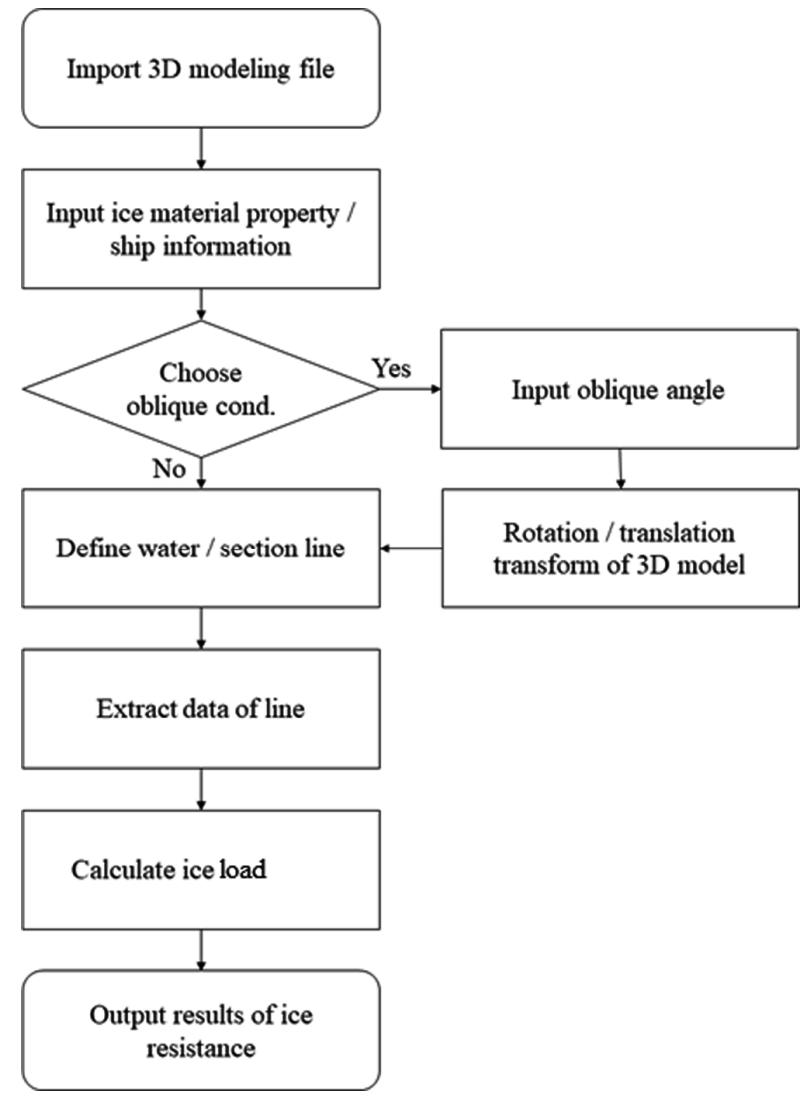

Fig. 6 Flowchart of estimation for the ice load

동일한 순서이지만, 3D모델에 대한 선형정보가 Fig. 3과 Fig. 5 에 보인 바와 같이 사항각도에 대한 새로운 정보로 변형되어 경험식 모듈의 입력값으로 적용된다.

Fig. 7은 추진방향 또는 얼음의 진행방향에 따라 추출된 Section line, Water line 데이터를 나타낸 것으로 좌표값 $(x, y, z)$ 법선벡 터 $\left(n_{x}, n_{y}, n_{z}\right)$, 그리고 기준축과의 각도 $(\alpha, \beta, \gamma)$ 가 사항각도만큼 회전변환되며, 변환된 사항조건의 선형정보는 빙 하중 계산모듈 을 통해 최종적으로 사항조건의 빙 제거 하중 및 부력 하중 추정 에 사용된다. 

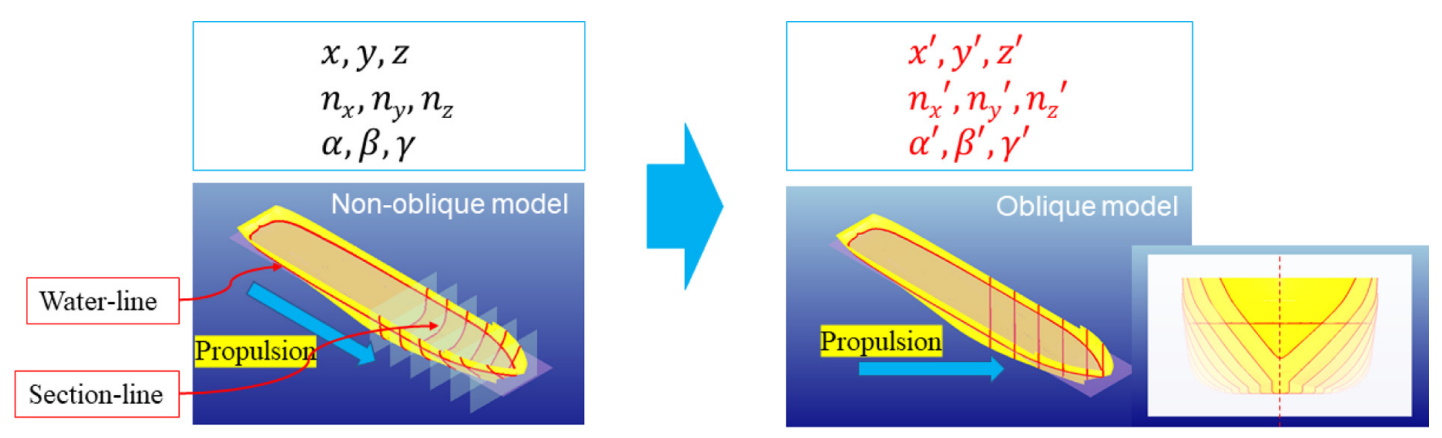

Fig. 7 Extraction of data with 3D model for ice load in oblique condition

\section{4. 사항조건의 빙 하중 추정}

본 논문에서는 사항각도가 빙 하중에 미치는 영향을 평가하 기 위하여 두 가지 변수를 고려하였다. 빙 두께와 선속이 증가 함에 따라 사항각도가 빙 하중에 미치는 영향을 분석하여 정리 하였으며, 이를 통해 경험식을 이용한 사항조건의 빙 하중 추정 연구방향을 제시할 수 있을 것으로 판단된다.

\section{1 사항조건 빙 하중 계산 조건}

평탄빙에서의 빙 두께 및 선속별 사항각도에 따른 빙 하중을 추정하여 각 인자가 빙 제거 하중과 부력 하중 성분에 미치는 영 향을 각각 평가하였다. 사항조건의 빙 하중 계산 조건을 Table 1 에 정리하였으며, Fig. 8은 사항조건의 빙 하중 추정 대상인 FPU 선형 정보를 나타낸다. 얼음 조건은 빙편(Pack ice) 직접도 $100 \%$ 인 Pre-sawn으로 하였으며, 빙 강도는 $800 \mathrm{kPa}$, 얼음과 물의 밀도 는 각각 $880,1000 \mathrm{~kg} / \mathrm{m}^{3}$, 탄성계수는 $2 \mathrm{GPa}$, 그리고 마찰계수 0.05 로 고려하였다. 빙 두께는 1 2m로 $0.5 \mathrm{~m}$ 간격, 선속은 $1 \sim 3 \mathrm{knots}$ $(1.852 \sim 5.556 \mathrm{~km} / \mathrm{h})$ 로 $1 \mathrm{knots}(1.852 \mathrm{~km} / \mathrm{h})$ 간격으로 빙 하중을 추정 하였으며, 사항각도는 $0^{\circ} \sim 30^{\circ}$ 로 $10^{\circ}$ 간격을 고려하였다.

Table 1 Input variables for calculation of ice load in oblique condition

\begin{tabular}{cc}
\hline \hline Items & Values \\
\hline Ship speeds & $1 \sim 3$ knots $(1.852 \sim 5.556 \mathrm{~km} / \mathrm{h}$ ) \\
(interval: 1 ) \\
Flexural Strength & $800 \mathrm{kPa}$ \\
Ice thickness & $1 \sim 2 \mathrm{~m}$ (interval: 0.5 ) \\
Elastic modulus & $2 \mathrm{GPa}$ \\
Friction coefficient & 0.05 (Ice and Ship) \\
Density & 880 (ice), 1000 (Water) $\mathrm{kg} / \mathrm{m}^{3}$ \\
\hline
\end{tabular}

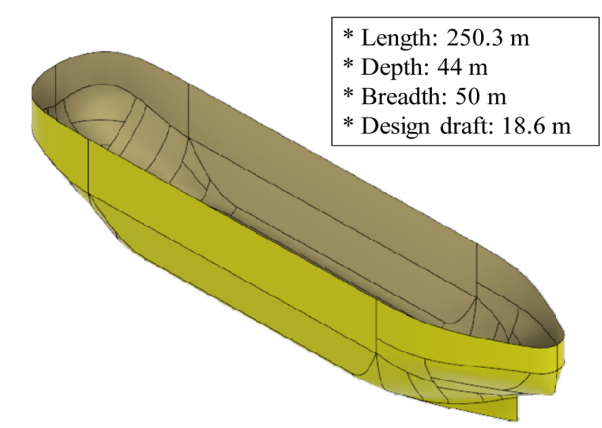

Fig. 8 Information of the FPU

\section{2 사항각도와 빙 두께가 빙 하중에 미치는 영향}

선속이 $2 \mathrm{knots}(3.704 \mathrm{~km} / \mathrm{h})$ 일 때, 사항각도가 증가함에 따라 빙 두께별로 Pre-sawn의 빙 하중을 추정하여 Fig. 9에 정리하였다. Spencer의 빙 하중 추정 이론을 기반으로, 유체 하중과 쇄빙 하 중을 제외한 2 개의 독립적인 빙 하중 성분들(빙 제거 하중, 부 력 하중)의 합으로 전체 빙 하중을 나타내었다.

사항각도가 증가함에 따라 빙 제거 하중 및 부력 하중은 전체 적으로 증가하였으나, 사항각도에 따른 증가량은 다르게 나타 났다. Fig. 9(a)는 빙 제거 하중을 나타낸 것으로 사항각도가 $10^{\circ}$ 씩 증가함에 따라 빙 제거 하중은 두께와 상관없이 평균 약 2.6 배 증가하였으나, 상대적으로 부력 하중은 증가량은 평균 약 1.01 배로 나타났다(Fig. 9(b) 참조). 이는 두께와 상관없이 사항 각도가 빙 제거 하중이 미치는 영향이 부력 하중보다 큰 것을 알 수 있다. 그 이유는 사항조건의 빙 하중 계산 시 사항각도에 따라 Water line상의 선형 데이터의 변화량이 Section line상의 선형 데이터 변화량보다 크기 때문인 것으로 판단된다(Fig. 3과 Fig. 5 참조). 또한, 비사항조건(사항각도 $0^{\circ}$ )에서는 부력 하중이 빙 제거 하중보다 크게 계산되었으나, 사항각도 $10^{\circ}$ 이후부터 빙 제거 하중이 부력 하중보다 크게 계산되어 사항각도에 따라서 전체 빙 하중 대비 부력 하중 성분의 우선 위가 다르게 평가될 수 있음을 나타낸다.

Fig. 9(a)-9(b)에 나타난 바와 같이 빙 두께가 증가함에 따라 빙 제거 하중 및 부력 하중은 증가하였으며, 임의의 사항각도에 서 빙 두께에 따른 빙 제거 하중과 부력 하중의 증가량은 유사 하게 계산되었다. 빙 제거 하중은 빙 두께 $1.0 \mathrm{~m}$ 에서 $1.5 \mathrm{~m}$ 증가 시 모든 사항각도에서 약 1.5 배 증가하였으며, 빙 두께 $1.5 \mathrm{~m}$ 에 서 $2 \mathrm{~m}$ 증가 시 모든 사항각도에서 약 1.3 배 증가하였다. 부력 하중도 모든 빙 두께에서 같은 경향을 보이고 있으며, 정략적으 로도 빙 두께 증가에 따른 부력 하중 증가량은 유사한 값으로 평가되었다.

Fig. 9(c)는 사항각도가 증가함에 따라 빙 두께별 Pre-sawn의 전체 빙 하중을 나타낸 것으로, 빙 제거 하중은 전체 빙 하중에 서 차지하는 비중이 부력 하중에 비해 상대적으로 크고, 사항각 도에 따른 증가량도 많기 때문에 빙 제거 하중 그래프 경향과 비슷하게 나타남을 알 수 있다. 모든 사항각도에 대하여 부력 하중이 전체 빙 하중에서 차지하는 비율은 최대 약 $10 \%$ 미만으 로 평가되며, 이는 사항조건을 고려하여 Pre-sawn의 전체 빙 하 중을 평가 시 빙 제거 하중을 최우선적으로 고려해야 한다. Fig. 10 은 빙 두께에 따른 사항각도별 Pre-sawn의 빙 하중을 정리한 


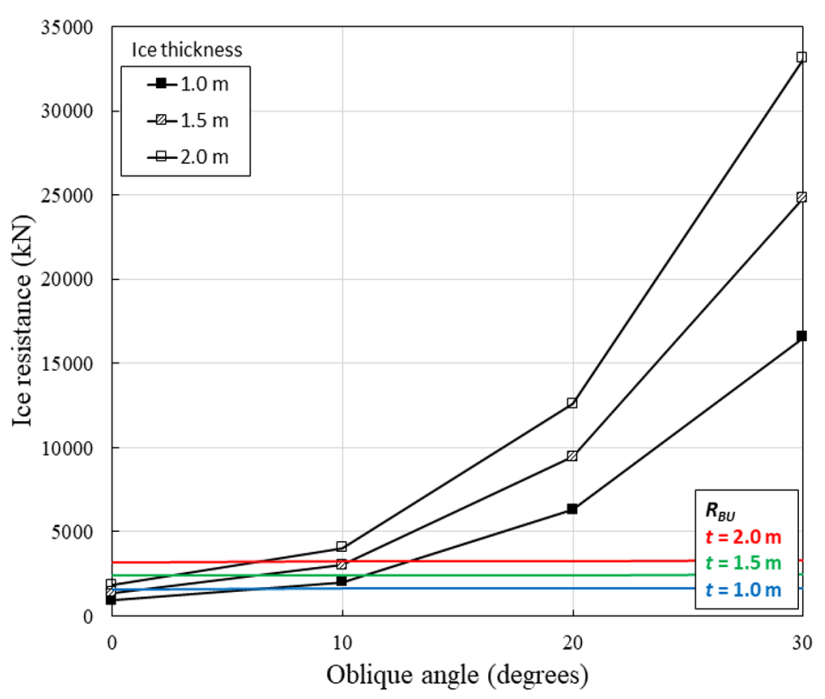

(a) Clearing (vs buoyancy)

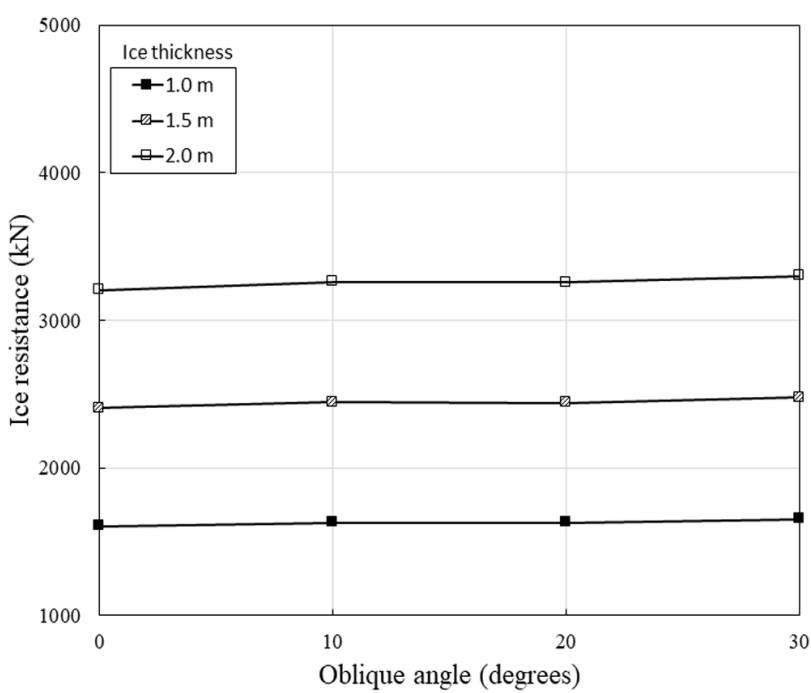

(b) Buoyancy

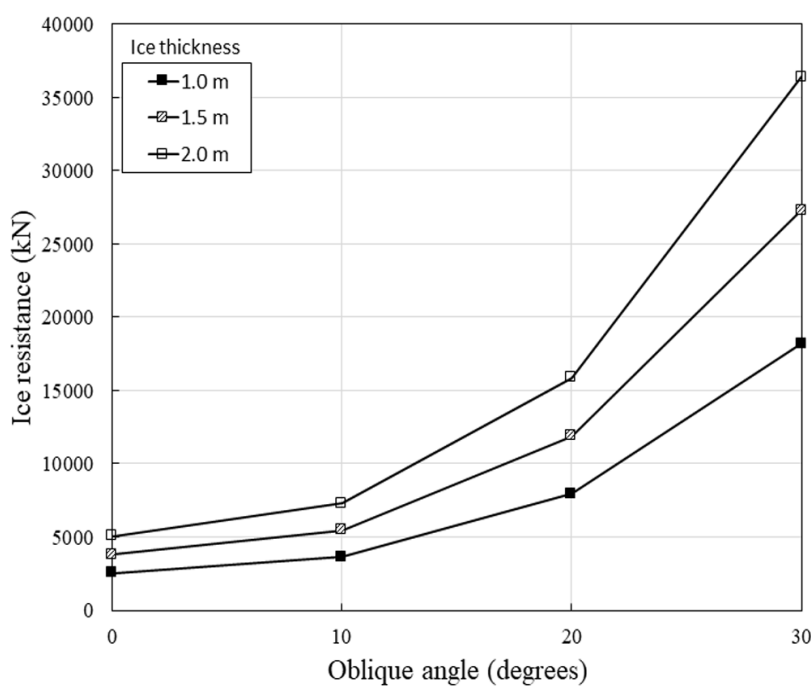

(c) Total

Fig. 9 The ice loads with oblique angles (ice thickness $=1,1.5$, and $2 \mathrm{~m}$ )

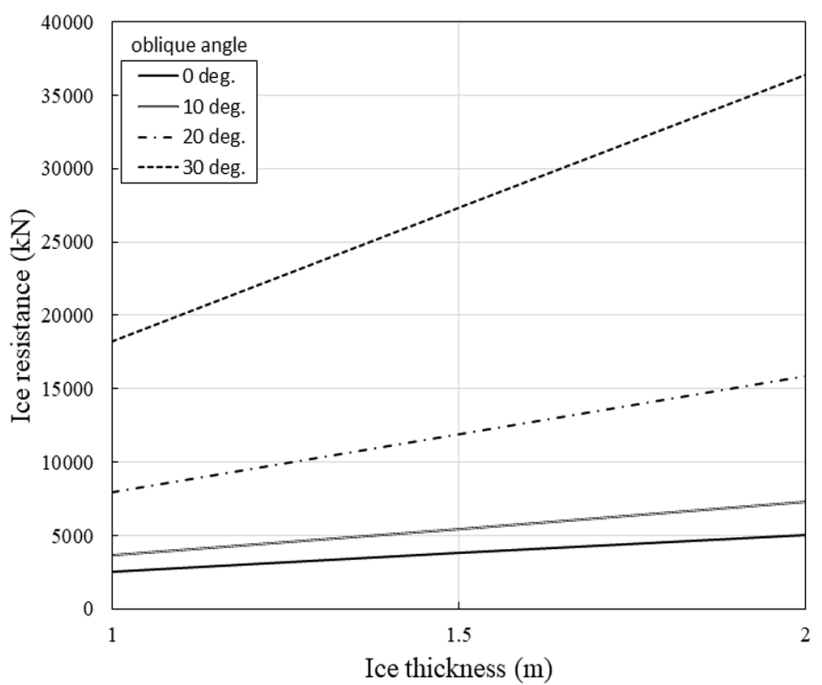

Fig. 10 Variations of the pre-sawn ice load with ice thickness

것으로, 빙 두께에 따른 전체 빙 하중의 증가율은 선형적으로 나타났으며, 빙 두께에 따른 전체 빙 하중은 사항각도가 $10^{\circ}$ 씩 증가함에 따라 최소 약 1.4 배에서 최대 2.3 배 증가하는 것으로 평가되었다.

\section{3 선속과 사항각도가 빙 하중에 미치는 영향}

빙 두께가 $1.5 \mathrm{~m}$ 일 때, 사항각도가 증가함에 따라 선속별로 Pre-sawn의 빙 제거 하중 및 부력 하중을 추정하여 Fig. 11에 정 리하였으며, 앞장에서 언급한바와 같이 유체 하중과 쇄빙 하중 을 제외한 2 개의 독립적인 빙 하중 성분들(빙 제거 하중, 부력 하중)의 합으로 전체 빙 하중을 계산하였다.

사항각도가 증가함에 따라 빙 제거 하중 및 부력 하중은 전체 적으로 증가하였으나, Fig. 11(b)에 나타난 바와 같이 사항각도 $30^{\circ}$ 도 증가 시 부력 하중의 증가량은 최대 약 $100 \mathrm{kN}$ 미만으로 빙 제거 하중에 비해 상대적으로 적은 증가량을 나타냈다. 또 한, 사항각도 $10^{\circ}$ 에서 $20^{\circ}$ 구간의 증가량이 다른 구간 $\left(0^{\circ} \sim 10^{\circ}, 20\right.$ $\left.{ }^{\circ} 30^{\circ}\right)$ 보다 상대적으로 적게 평가되었는데, 그 이유는 FPU 선형 의 기하학적 특성이 기인한 것으로 판단된다. 한편 Fig. 11(a)에 서 빙 제거 하중은 사항각도가 $10^{\circ}$ 씩 증가함에 따라 빙 제거 하 중은 선속과 상관없이 평균 약 2.6 배 증가하였다. 이는 앞장에 서 언급한 두께에 상관없이 사항각도가 증가함에 따라 빙 제거 하중이 평균 약 2.6배 증가한 경향과 유사하나, 정략적인 빙 제 거 하중값은 차이가 있었다. 그리고 사항각도 $0^{\circ}$ 에서는 부력 하 중이 빙 제거 하중보다 모든 속도에 대해서 크게 예측되었으나, 사항각도가 증가함에 따라 반대의 경향을 나타냈다.

선속의 영향을 살펴보면 선속이 증가함에 따라 빙 제거 하중 은 증가하였으나, 부력 하중은 변화가 없는 결과를 나타냈다. 그 이유는 식 (6)에서 부력 하중 계산 시에 속도를 고려하지 않 기 때문으로, 부력 하중 추정식에서는 빙편이 정적상태에서 흘 수이하의 선저 전체를 감싸고 있다고 가정하기 때문이다. 반면 에 빙 제거 하중은 속도를 고려한 프루드수 파라미터를 사용하 고 있다. 임의의 사항각도에서 빙 두께에 따른 빙 제거 하중은 Fig. 11(a)에 나타난 바와 같이 선속 $1 \mathrm{knots}(1.852 \mathrm{~km} / \mathrm{h})$ 에서 $2 \mathrm{knots}(3.704 \mathrm{~km} / \mathrm{h})$ 증가 시 모든 사항각도에서 약 2 배 증가하였 


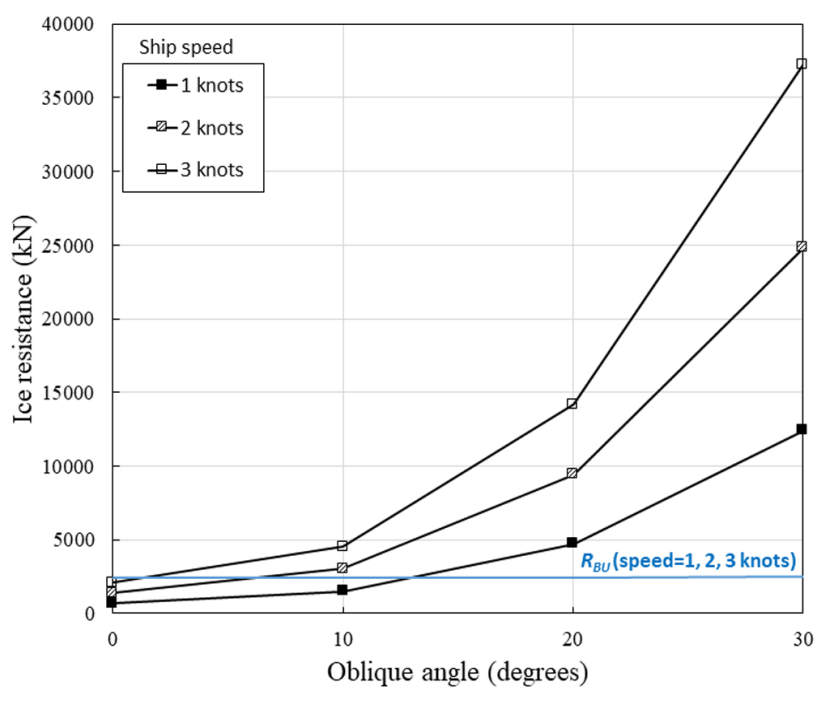

(a) Clearing (vs buoyancy)

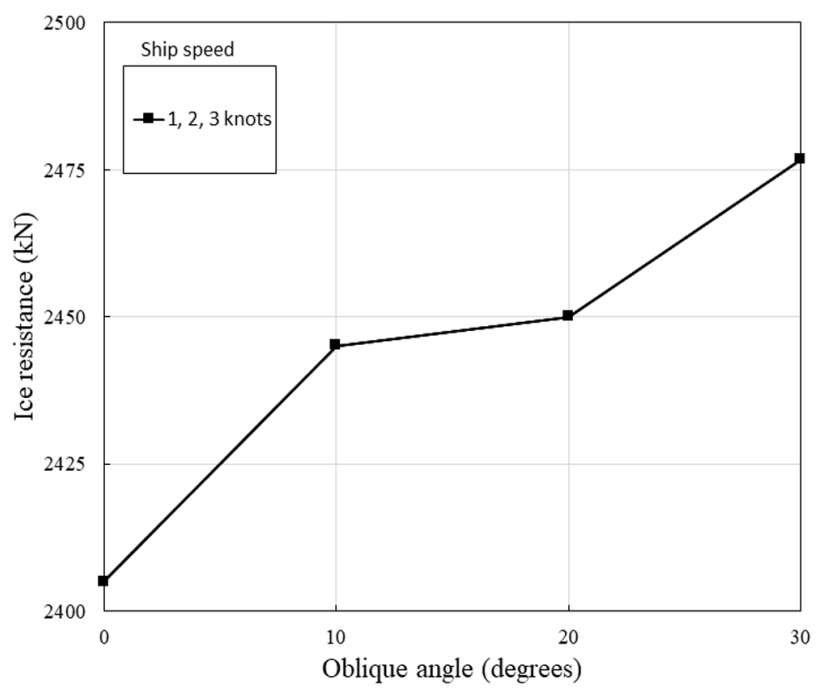

(b) Buoyancy

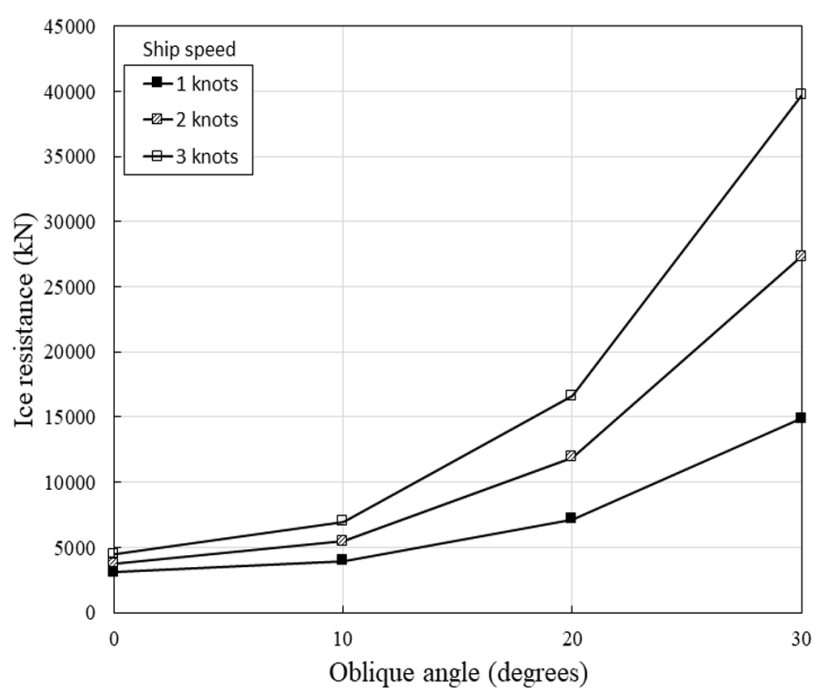

(c) Total

Fig. 11 The ice load with oblique angles (ship speeds $=1,2$, and 3 knots)

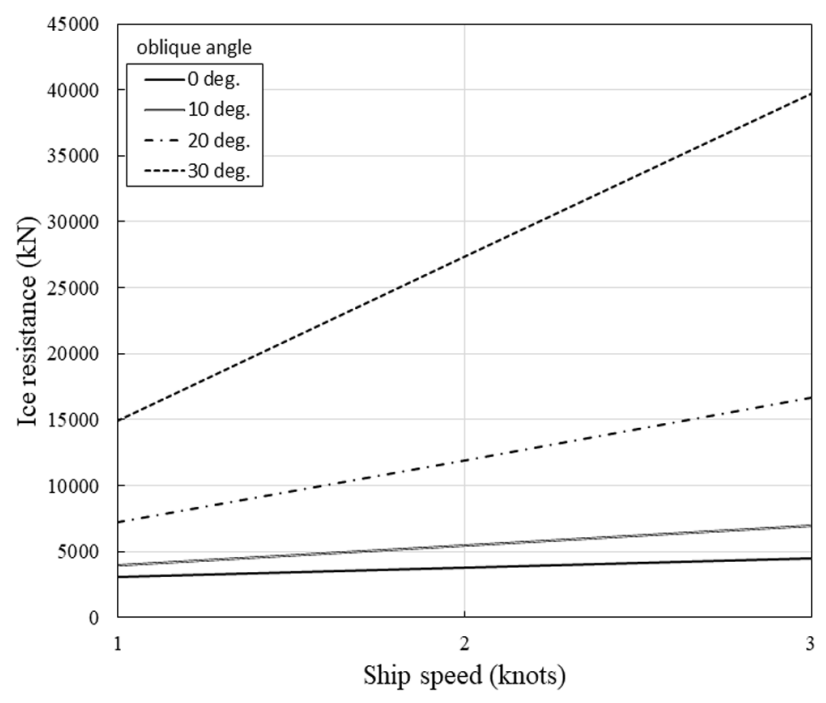

Fig. 12 Variations of the pre-sawn ice load with ship speeds

으며, 빙 두께 $2 \mathrm{knots}(3.704 \mathrm{~km} / \mathrm{h})$ 에서 $3 \mathrm{knots}(5.556 \mathrm{~km} / \mathrm{h})$ 증가 시 모든 사항각도에서 약 1.5 배 증가하였다.

Fig. 11(c)는 사항각도가 증가함에 따라 선속별 Pre-sawn의 전 체 빙 하중을 나타낸 것이며, 선속과 상관없이 부력 하중이 일 정하므로 선속이 증가함에 따라 전체 빙 하중에서 부력 하중이 차지하는 비중은 감소한다. Fig. 12는 선속에 따른 사항각도별 Pre-sawn의 빙 하중을 정리한 것으로, 선속에 따른 전체 빙 하중 의 증가율은 앞장에서 언급한 두께에 따른 경향과 비슷하게 선 형적으로 나타났으며, 선속에 따른 전체 빙 하중은 사항각도가 $10^{\circ}$ 씩 증가함에 따라 최소 2.2 배에서 최대 약 3.1 배 증가하는 것 으로 평가되었다. 이것은 두께에 따른 Pre-sawn의 빙 하중 증가 량보다 많은 값으로 선속이 두께보다 사항각도에 따른 Pre-sawn 의 빙 하중 결과에 미치는 영향이 더 크다고 판단된다.

\section{6. 결 론}

본 논문에서는 극지에서 운용하는 해양구조물에 대해 사항조 건에 따른 빙 하중 산정의 필요성을 설명하였으며, 사항조건의 빙 하중 산정을 위해서 비사항조건(일반적인 쇄빙선)의 빙 하중 추정 이론을 사항조건에 적합하도록 수정하였다. 기 검증된 빙 하중 산정 프로그램을 이용하여 사항조건의 빙 하중 추정 알고 리즘을 제시하였으며, 이론적인 설명을 통해 이 알고리즘의 타 당성을 검토하였다. FPU 선형에 대한 다양한 사항조건에 대해 서 Pre-sawn의 빙 전체 하중을 추정하기 위하여 빙 제거 하중 및 부력 하중을 계산하였으며, 다음과 같이 결론을 요약 정리하 였다.

(1) FPU 선형의 경우, 빙 두께 및 선속에 상관없이 사항각도 가 증가함에 따라 빙 제거 하중과 부력 하중은 일정한 증가율 로 커졌으며, 빙 제거 하중의 증가량은 비선형적으로 많아졌으 나, 부력 하중의 증가량은 매우 적은 것으로 평가되었다. 따라 서 사항각도에 따른 Pre-sawn의 빙 하중 산정 시 부력 하중은 전체 빙 하중에서 작은 비중을 차지하며, 이는 사항각도에 따른 선형정보(Section line)의 비대칭성이 부력 하중 결과에 미치는 영향은 작은 것으로 판단된다. 
(2) 빙 두께에 따른 Pre-sawn의 빙 하중 증가량은 최대 사항각도 $30^{\circ}$ 에서 최대 약 1.5 배로 평가되었으며, 선속에 따른 Pre-sawn의 빙 하중 증가량은 최대 사항각도 $30^{\circ}$ 에서 최대 약 2 배로 평가되었 다. 따라서 선속이 사항각도에 따른 Pre-sawn의 빙 하중에 미치는 영향이 빙 두께보다 더 크게 작용할 것으로 판단된다.

따라서 본 논문은 경험식을 이용한 사항조건의 빙 하중을 추 정 방법을 제시하였고, $\mathrm{FPU}$ 의 사항조건 빙 하중 추정하여 사항 각도에 따른 영향을 평가하였다. 이 결과는 FPU의 사항조건 빙 하중 추정 시 활용될 수 있을 것으로 판단된다. 또한, 추후 이에 대한 모형실험과 비교검증을 통해 사항조건에 따른 정량적인 빙 하중을 도출할 수 있을 것이라고 예상되며, 향후 다른 극지 해양구조물의 사항조건 빙 하중 추정 시에도 활용될 수 있을 것이다.

\section{후기}

이 논문은 2017년도 해양수산부 재원으로 한국해양과학기술 진흥원 및 2017년도 산업통상자원부 연구비 지원에 의한연구임. (‘북극항로 운항선박용 항해안전지원시스템 개발' ‘위치유지와 계류 시스템을 적용하여 $\mathrm{ARC7}$ 조건에서 연중운용이 가능한 북 극해 기반 부유식 해양구조물 형상 개발')

\section{References}

Jian, H., Li, Z., 2015. Experimental And Numerical Study On Ice Resistance For Icebreaking Vessels. International Journal of Naval Architecture and Ocean Engineering, 7(5), 626-639.

Jeong, S.Y., Jang, J.H., Kang, K.J. Kim, H.S., 2017. Implementation Of Ship Performance Test In Brash Ice Channel. Ocean Engineering, 140, 57-65.
Li, Z., Kaj, R., Rüdiger, B.P., Torgeir, M., Biao, S., 2013. Experiments On Level Ice Loading On An Icebreaking Tanker With Different Ice Drift Angles. Cold Regions Science and Technology, 85, 79-93.

Kim, H.S., Ryu, C.H., Park, K.D., 2013. Development of Ice Resistance Estimation Program of Icebreaking Vessels Using Ship CAD Data. Proceedings of the Society of CAD/CAM Conference, Pyeongchang, Korea, 501-504.

Kim, H.S., Ryu, C.H., Park, K.D., Lee, J., 2014. Development of Estimation System of Ice Resistance with Surface Information of Hull Form. Journal of Ocean Engineering and Technology, 31(5), 371-377.

Kim, H.S., Jeong, S.Y., Woo, S.H., Han, D., 2017. Study On The Procedure To Obtain An Attainable Speed In Pack Ice. International Journal of Naval Architecture and Ocean Engineering, in Press. https://doi.org/10.1016/j.ijnaoe.2017. 09.004 .

Enkvist, E., 1972. On the Ice Resistance Encountered by Ships Operating in the Continuous Mode of Icebreaking. The Swedish Academy of Engineering Sciences, 24.

Poznyak, I.I., Ionov, B.P., 1981. The Division Of Icebreaking Resistance Into Components. Proceeding of the $6^{\text {th }}$ STAR Symposium, New York, U.S., 249-252.

Spencer, D., 1992. A Standard Method for the Conduct and Analysis of Ice Resistance Model Tests. Proceeding of the $23^{\text {rd }}$ American Towing Tank Conference, New Orleans U.S., 301-307.

Shimanskii, Yu.A., 1938. Conditional Standards Of Ice Qualities Of A Ship. Engineering Consulting and Translation Center (ECTC), New York. 